\title{
QUANTIFICAÇÃO DE ANTOCIANINAS DOS EXTRATOS DE EMBIRATANHA (Pseudobombax marginatum)
}

\author{
M. A. G. MENEZES, F. B. OliVeiRA NETO, L. M. BERTINI, L. A. ALVES ${ }^{*}$ e F. F. M SILVA \\ Instituto Federal do Rio Grande do Norte (IFRN) - Campus Apodi \\ leonardo.alcantara@ifrn.edu.br*
}

Artigo submetido em setembro/2014 e aceito em fevereiro/2015

DOI: $10.15628 /$ holos.2015.2459

\section{RESUMO}

As antocianinas compõem uma classe de metabólitos secundários no qual, inúmeras vezes, é associado com a coloração de espécies vegetais. Esse grupo encontra-se presente em diversas partes da planta, tais como: caule, flor, fruto, folha, entre outros. Com isso, o presente trabalho tem como objetivo a quantificação de antocianinas dos extratos em etanol-água das diversos partes (Galhos, Caule, Raiz e Flores), da Embiratanha (Pseudobombax marginatum). Foram avaliados os extratos com o intuito de estimar a concentração de antocianinas presente nos mesmos. Dentre as partes supracitadas, o Caule da embiratanha apresentou a maior concentração de antocianinas de 0,49/100g do material. $\mathrm{O}$ trabalho foi de grande importância para a quantificação de antocianinas da Pseudobombax marginatum, uma planta com fins terapêuticos amplamente utilizada na medicina popular.

PALAVRAS-CHAVE: embiratanha, quantificação de antocianinas, metabólitos secundários.

\section{QUANTIFICATION OF ANTHOCYANINS OF EMBIRATANHA (Pseudobombax marginatum)}

\begin{abstract}
Anthocyanins is a class of secondary metabolites which often is associated with plant species colors. This group is present in various parts of the plant such as stem, flower, fruit, leaf, among others. In this work, the extracts anthocyanin contents were evaluated in ethanol-water members (Branches, Stem, Root and Flower) of the Embiratanha - Pseudobombax
\end{abstract}

marginatum. Extracts were evaluated in order to estimate the anthocyanins concentrations present in the same. Among the members, the embiratanha's Stem showed the highest anthocyanins content of 0.49 / 100g of material. This study was of great importance for the quantification of Pseudobombax marginatum, a widely used plant for therapeutic purposes.

KEYWORDS: embiratanha, anthocyanins contents, secondary metabolites. 


\section{INTRODUÇÃO}

A espécie Pseudobombax marginatum (A.St.-Hil., Juss. \&Cambess.) A. Robyns é uma planta da família Malvaceae, vastamente encontrada no Nordeste brasileiro, sendo conhecida popularmente como embitaratanha, embiruçu, imbiratanha, paina-de-arbusto (DUARTE, 2006) (Figura 1). Devido a suas propriedades farmacológicas, trata-se de uma espécie muito utilizada, sendo que a água da casca da embiratanha pode ser usada como anti-inflamatório, contraceptivo e ainda, para aliviar úlceras e gastrites (PAULINO et al., 2012).

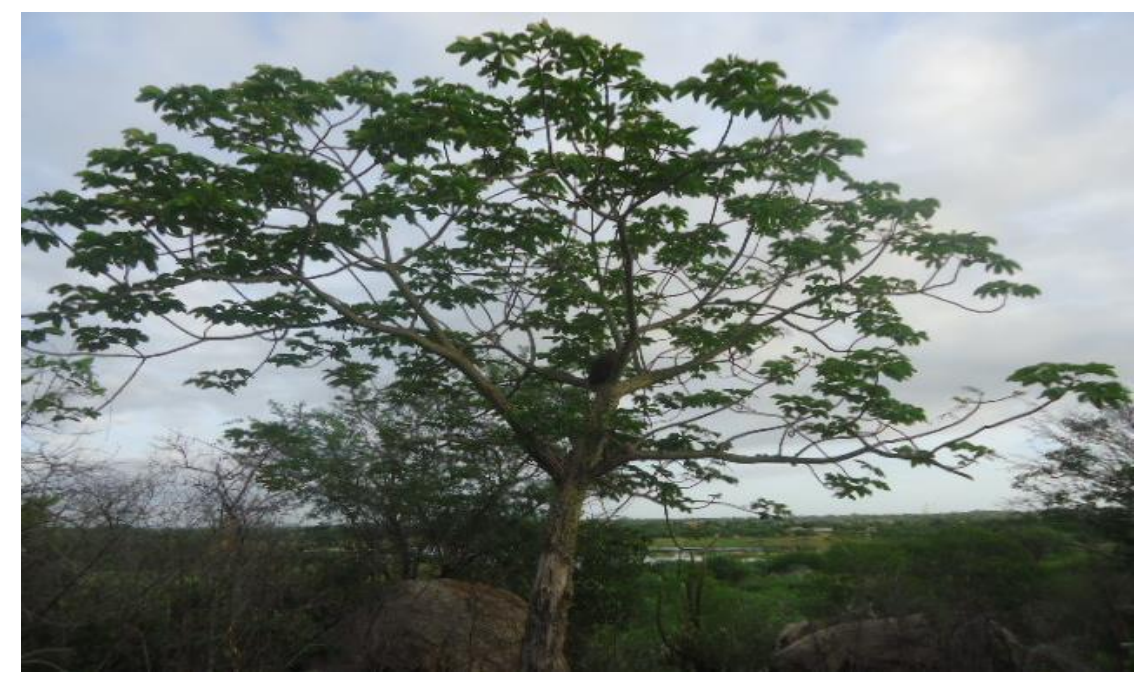

Figura 1- Embiratanha (Pseudobombax marginatum)

O uso de plantas com fins terapêuticos iniciou-se há milhares de anos por várias populações com o intuito de tratar causas e sintomas de diversas doenças. Mesmo com os grandes avanços da medicina moderna, os produtos naturais continuam sendo utilizados, visto que cerca de $30 \%$ de todas as drogas avaliadas como agentes terapêuticos são derivados de metabólitos secundários (CALIXTO, 2005; VEIGA-JUNIOR, MELLO, 2008).

Dentre os grupos de compostos fenólicos, classe de metabólitos secundários amplamente encontrada em espécies vegetais característicos por apresentarem pelo menos um anel aromático com um hidrogênio substituído por um grupamento hidroxila, destacam-se os flavonoides que podem ser encontrados em todas as partes das plantas (ARAYA, 20014; SIMÕES; SCHENKEL, 2004).

Os flavonoides são considerados potentes antioxidantes naturais, isso se deve aos grupos hidroxila ligados à estrutura do anel aromático. A capacidade antioxidante dos flavonoides geralmente aumenta com o aumento dos grupos hidroxila resultados do favorecimento na deslocalização de elétrons nos núcleos aromáticos, permitindo assim a estabilidade do radical (ALMEIDA, 2006; BALASUNDRAM; SUNDRAM; SAMMAN, 2006).

As antocianinas (Figura 2) são compostos pertencentes ao grupo dos flavonoides e constituem grupos de pigmentos responsáveis por grande parte das cores em flores, frutas, folhas, caules e raízes de plantas (TEIXEIRA, 2008). Umas das principais propriedades das antocianinas é a diversidade de cores, o que as torna materiais potenciais no uso como indicadoras de pH (TERCl; ROSSI, 2002). A cor das antocianinas depende diretamente de sua 
estrutura química, do número e da posição dos grupos " $R$ " que podem ser substituídos por hidroxilas e metoxilas que a compõem (LOPES, 2002).

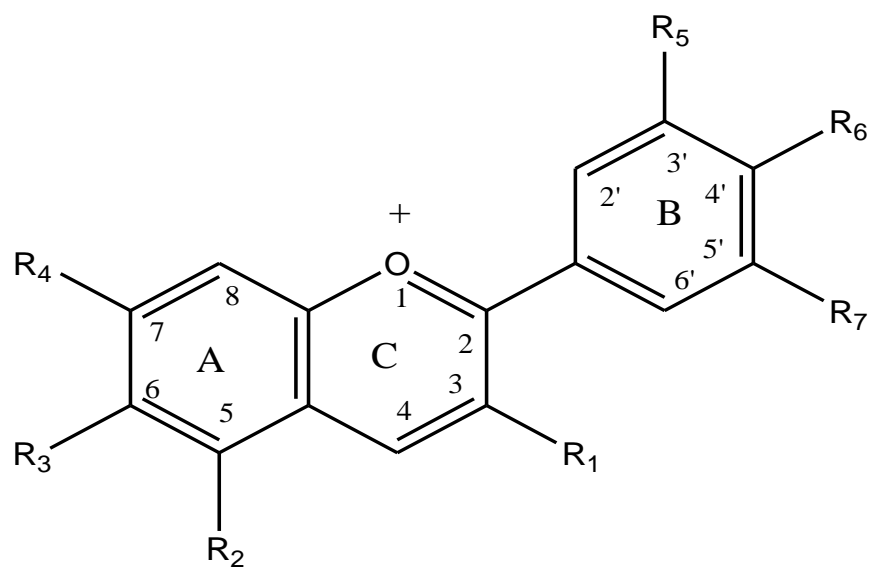

Figura 2- Esqueleto químico básico das antocianinas

Um dos fatores mais importantes para a pigmentação da flor e da fruta é o pH, no qual a variação da coloração das antocianinas depende da sua estabilidade e o pH do meio em que estão inseridas (BRILHANTE, 2013). Os flavonois, por sua vez, atuam na pigmentação das antocianinas através de mecanismo de complexação intermolecular, tornando mais estável a molécula antociânica. Dentre os compostos que exibem esta ação, os flavonois são os mais eficazes (MALIEN-AUBERT; DANGLES; AMIOT, 2001).

A partir do exposto, o presente trabalho tem como finalidade avaliar a concentração de antocianinas presentes em diferentes partes da embiratanha (Pseudobombax marginatum). Para a obtenção dos resultados foram realizados testes de quantificação de antocianinas dos galhos, cascas, raízes e flores.

\section{MATERIAIS E MÉTODOS}

No presente trabalho foram avaliadas as concentrações de antocianinas presentes em diversas partes da embiratanha (Pseudobombax Marginatum), tais como caule, galhos, raiz e flores do vegetal. O material foi coletado no Sítio Melancias no município de Apodi-RN no mês de Abril de 2014 no período vespertino.

As amostras foram previamente trituradas e pesadas para posteriormente serem adicionados $80 \mathrm{~mL}$ de solvente extrator contendo Etanol e Água (70/30). Em seguida foi adicionado $\mathrm{HCl}$ a mistura suficiente para ajustar o $\mathrm{pH}$ do meio para 2,0. 0 material foi deixado em repouso por 24 horas a $5{ }^{\circ} \mathrm{C}$, ao abrigo da luz, para extração. Após esse período o mesmo foi prensado manualmente com bastão de vidro e filtrado, com a finalidade de reter o resíduo, e o extrato transferido para balão volumétrico de $100 \mathrm{~mL}$, tendo seu volume completado com o solvente extrator formando o extrato concentrado. O conteúdo do balão foi centrifugado a 2000 rpm, por 10 minutos e o sobrenadante foi filtrado. Após a filtração, o extrato foi purificado, extraindo-se (três extrações sucessivas) o conteúdo de clorofila com auxílio de $100 \mathrm{~mL}$ de mistura de Éter Etílico e Éter de Petróleo (1 /1) (TEXEIRA et al., 2008).

A concentração de antocianinas nos extratos vegetais foi analisada por método espectrofotométrico. A absorbância foi avaliada em espectrofotômetro UV marca TEM-KA T2000, efetuando-se leituras em comprimento de onda de $535 \mathrm{~nm}$. O conteúdo total de 
antocianinas foi expresso em mg de antocianinas/100g da fração da amostra analisada (galhos, folhas, caule e raiz).

O método consiste da transferência quantitativa de uma alíquota (Valq) do extrato concentrado para balão volumétrico de $10 \mathrm{~mL}$, tendo o volume completado com solução de etanol $95 \%$ e ácido clorídrico 1,5 mol. $\mathrm{L}^{-1}$ (85/15), formando desta maneira, o extrato Diluído (ED). Os valores de absorbância (DO) foram contrastados com os valores em brancos (Solução Etanol$\mathrm{HCl} 1,5$ mol. $\left.\mathrm{L}^{-1}(85 / 15)\right)$. O cálculo da concentração de Antocianinas Totais (Ant. T) por 100 gramas da fração avaliada foi efetuado de acordo com a Figura 3.

$$
\text { Ant. } \mathrm{T}\left(\mathrm{mg} / 100 \mathrm{~g} \text { da amostra) }=\frac{\mathrm{DO} \times \mathrm{VE} 1 \times \mathrm{VE} 2 \times 1000}{\text { Valq } \times \mathrm{m} \times 982}\right.
$$

Figura 3- Quantificação das antocianinas

Onde,

DO: Densidade ótica de extrato diluído

VE1: Volume total do extrato concentrado

VE2: Volume total do extrato diluído

Valq: Volume da alíquota utilizado na diluição do extrato concentrado

m: Massa da amostra

982: Coeficiente de Extinção Médio de antocianinas para o Método pH único

\section{RESULTADOS E DISCUSSÃO}

Após extração das antocianinas presentes nos extratos em etanol e água dos membros supracitados, a partir da utilização da metodologia citada anteriormente foi possível a análise de sua concentração. No método utilizado, denominado método de pH único para quantificação de antocianinas (TEIXEIRA et al., 2008), verificou-se as seguintes concentrações de antocianinas com segue a Tabela 1.

Tabela 1- Avaliação da concentração de antocianinas

\begin{tabular}{cc}
\hline $\begin{array}{c}\text { Membros da Pseudobombax } \\
\text { Marginatum }\end{array}$ & $\begin{array}{c}\text { Concentração de antocianinas } \\
\text { (mg /100g do extrato bruto) }\end{array}$ \\
\hline Galhos & 0,38 \\
Caule & 0,49 \\
Raiz & 0,24 \\
Flores & 0,01 \\
\hline
\end{tabular}

Fonte: Próprio autor.

É possível constatar que as concentrações de antocianinas dos membros da embiratanha, não apresentaram resultados muito significativos quando comparados com os testes feitos por Teixeira (2008). No trabalho os autores obtiveram concentrações de antocianinas que variaram de 12,67 mg Ant/100g da amostra do Romã a 492,74mg /100g a amostra de Jabuticaba. Acreditase que isso se deu devido a cor dos extratos, os extratos com cores mais fortes apresentam um 
grande indício da presença de antocianinas. Os extratos da embiratanha apresentaram cores variando de verde-claro a incolor, o que pode justificar o baixo valor de sua concentração de antocianinas, pois estes possuem uma relação direta com a coloração dos extratos.

Por outro lado, estes valores são semelhantes aos obtidos por Brilhante (2013) nas espécies mangerioba do Pará (Senna alata) e mini-girassol (Tithonia diversifolia) com valores de 0,16 mg Ant/100g e 0,22 mg Ant/100g, respectivamente.

É importante destacar que as quantidades de antocianinas podem ser influenciadas por diversos fatores, tais como, o clima, a temperatura e iluminação, que, dessa forma, dificultam a comparação entre diferentes cultivos de uma mesma planta. (TEIXEIRA et al., 2008).

\section{CONCLUSÃO}

A partir da realização deste trabalho, pode-se concluir que o material vegetal estudado, apresenta considerável concentração de antocianinas quando comparados com outros estudos encontrados na literatura. Dentre os membros da espécie em estudo, os caules e galhos apresentaram os resultados mais relevantes para o estudo em questão, com valores de antocianinas de 0,49 e $0,38 \mathrm{mg} / 100 \mathrm{~g}$, respectivamente. Conclui-se que os valores baixos nas concentrações de antocianinas obtidos podem ser resultado da ausência de uma coloração forte no material estudado, muitas vezes um indicativo da presença das mesmas.

\section{REFERÊNCIAS BIBLIOGRÁFICAS}

1. ALMEIDA, J. M. D.; SANTOS, R, J. DOS; GENOVESE, M. I.; LAJOLO, F.M. Avaliação da atividade antioxidante utilizando sistema ß-caroteno/ácido linoléico e método de sequestro de radicais DPPH. Ciência e Tecnologia de Alimentos, Campinas, v. 26, n. 2, p. 446-452, abri. -jun. 2006.

2. ARAYA, H. Studies on annonaceous tetrahydrofuranic acetogenins from Annona squamosa $L$. seeds. Bull. Natl. Inst. Agro-Environ. Sci., v. 23, p. 77-149, 2004.

3. BALASUNDRAM, N.; SUNDRAM, K.; SAMMAN, S. Phenolic compounds in plants and agriindustrial by-produts: Antioxidant activity, occurrence, and potential uses. Food Chemistry, v. 99, p. 191-203, 2006.

4. BRILHANTE, S. E. T. Determinação do teor de antocianinas e sua influência na capacidade indicadora de $\mathrm{pH}$ em extratos de flores do Rio Grande do Norte. Trabalho de Conclusão de Curso. Instituto Federal de Educação, Ciência e Tecnologia do Rio Grande do Norte. Apodi, Rio Grande do Norte. 2013.

5. CALIXTO, J. B. Twenty-five years of research on medicinal plants in Latin America: apersonal review. Journal Ethnofarmacology, v. 100, p. 131-134, 2005.

6. DUARTE, M. C. Diversidade de Bombacaceae Kunth no estado de São Paulo 2006. 112 p. Dissertação (Mestrado em Biodiversidade Vegetal e Meio Ambiente) - Instituto de Botânica da Secretaria do Meio Ambiente, São Paulo, 2006.

7. LOPES, T. J. Adsorção de antocianinas do repolho roxo em argilas. 140f. Dissertação (Mestrado em Engenharia Química) - Departamento de Engenharia Química, Universidade Federal de Santa Catarina, Florianópolis, 2002. 
8. MALIEN-AUBERT, C.; DANGLES, O.; AMIOT, M.J. Color stability of commercial anthocyanin: based extract in relation of the phenolic composition. Journal of Agricultural and Food Chemistry, Washington, v.49, p.170-176, 2001.

9. SIMÕES, C. M. O.; SCHENKEL, E. P. Farmacognosia: da planta ao medicamento. Florianópolis, Ed. da UFSC, 2004.

10. TEXEIRA, L.N.; STRINGHETA, P. C.; OLIVEIRA, F.A. de; Comparação de metódos para quantificação de antocianinas. Revista Ceres, v. 55, n. 4, p. 297-304, 2008.

11. TERCI, D. B. L.; ROSSI, A. V. Indicadores naturais de pH: usar papel ou solução? Química Nova [online], v. 25, n. 4, p. 684-688, 2002. Disponível em: <http://www.scielo.br/pdf/qn/v25n4/10546.pdf>. Acesso em: 09 Jul. 2013.

12. VEIGA-JUNIOR, V.F.; MELLO. J. C. P. As monografias sobre plantas medicinais. Revista Brasileira de Farmacognosia, v. 18, p. 464-471, 2008. 